\title{
Genetic structure of honeybee populations from southern Brazil and Uruguay
}

\author{
Nilza Maria Diniz ${ }^{1}$, Ademilson Espencer Egea Soares ${ }^{2}$, Walter Steve Sheppard ${ }^{3}$ \\ and Marco Antonio Del Lama ${ }^{4}$ \\ ${ }^{1}$ Departamento de Biologia Geral, Universidade Estadual de Londrina, Londrina, PR, Brazil. \\ ${ }^{2}$ Departamento de Genética, Faculdade de Medicina de Ribeirão Preto/USP, Ribeirão Preto, SP, Brazil. \\ ${ }^{3}$ Entomology Department, Washington State University, Pullman, WA, USA. \\ ${ }^{4}$ Departamento de Genética e Evolução, Universidade Federal de São Carlos, São Carlos, SP, Brazil.
}

\begin{abstract}
Apis mellifera scutellata was introduced to Brazil in 1956 and Africanized honeybee populations have now spread from Argentina to the southwestern United States. Temperate climatic restrictions seem to be a natural limit to Africanized honeybee expansion around parallels $35^{\circ}$ to $40^{\circ} \mathrm{SL}$. We used allozyme loci (Mdh-1 and $H$ k-1) and mtDNA haplotypes to characterize honeybee populations in southern Brazil and Uruguay and define a possible transition area between Africanized and European bees. Samples of 194 bee colonies were collected from ten localities between $30^{\circ}-35^{\circ} \mathrm{SL}$ and $52^{\circ}-59^{\circ} \mathrm{WL}$. The mtDNA restriction patterns of these colonies were obtained through digestion of the mitochondrial genome by Eco Rl, or by digestion by $\mathrm{Bgl} / /$ and Xba I of the cytochrome $\mathrm{B}$ locus and the COI-COII intergenic region, respectively. The distribution limit of African bee colonies, i.e., those populations with only the African mtDNA haplotype and with a high proportion of African genes as shown by allozyme analysis, is located in northern Uruguay, with a hybridization zone located farther south in Uruguay. A gradual cline from north to south was observed, confirmed by mtDNA, racial admixture, and genetic distance analyses. No evidence of either gametic disequilibrium between nuclear markers or cytonuclear disequilibrium among the nuclear and mtDNA genotypes was detected, suggesting that the hybridization process has been completed.
\end{abstract}

Key words: Africanized honeybees, transition area, South America, mtDNA, allozymes, population genetics.

Received: July 8, 2002; accepted: November 21, 2002.

\section{Introduction}

A sub-Saharan subspecies, Apis mellifera scutellata, was introduced to Brazil in Rio Claro, São Paulo state, in the mid-1950s to improve honey production in neotropical conditions (Kerr, 1967). Populations of Africanized honeybees, expressing scutellata-like reproductive, foraging, and defensive behavior, spread rapidly from that area to as far south as mid-Argentina and to southern Texas due to their high adaptability to tropical ecological conditions. During this expansion, they hybridized with European bees (A. $m$. ligustica, A. m. mellifera, and A.m. iberica) that had been in the region since the XVIII century. These Africanized bees arrived in the United States in 1990 and presently occupy part of the states of Texas, Arizona, New Mexico, and California (Rowell et al., 1993; Sanford, 1995).

Malate dehydrogenase $(M d h-1)$ and hexokinase (Hk-1) allozymes have usually been used to characterize $A$. mellifera populations or determine their racial composition

Send correspondence to Marco Antonio Del Lama. E-mail: dmdl@ power.ufscar.br.
(Badino et al., 1983; Sheppard and McPheron, 1986; Spivak et al., 1988; Lobo et al., 1989; Del Lama et al., 1988, 1990; Lobo, 1995). Nuclear and mitochondrial DNA polymorphisms (Hall, 1986, 1990; Smith and Brown, 1988; Hall and Muralidharan, 1989; Oldroyd et al., 1992; Sheppard et al., 1991a,b; Clarke et al., 2001), and, more recently, microsatellites (Estoup et al., 1993, 1994, Franck et al., 1998) have proven to be very useful molecular markers for honeybee population genetics.

Although they occupy a large area of South America, Africanized bees have not been able to colonize in southern latitudes greater than $35^{\circ}$. Morphometric and molecular studies carried out by Sheppard et al. (1991a) in samples from Argentina demonstrated no Africanized bees live beyond the area between the $30^{\circ}-35^{\circ} \mathrm{SL}$ parallels. This border zone lies a little farther to the south than that originally suggested by Kerr et al. (1982). However, mtDNA and morphometric analyses of 35 Uruguayan bee colonies revealed both hybrid and European bee colonies (Burgett et al., 1995). 
The present study, carried out to further characterize bee populations in southern Brazil and Uruguay, used nuclear ( $M d h-1$ and $H k$ ) and cytoplasmatic (mtDNA) genetic markers to establish more precisely the southern limit of Africanized honeybee expansion in South America.

\section{Material and Methods}

Samples of 194 colonies (50-100 adult workers) from ten localities in Southern Brazil and Uruguay were collected: Santa Maria $\left(29^{\circ} 42^{\prime} \mathrm{SL}, 53^{\circ} 40^{\prime} \mathrm{WL}\right), 19$ hives;

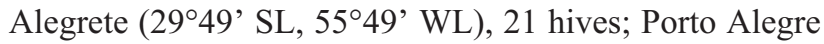
$\left(30^{\circ} 05^{\prime} \mathrm{SL}, 51^{\circ} 11^{\prime} \mathrm{WL}\right), 15$ hives; Rivera $\left(30^{\circ} 54^{\prime} \mathrm{SL}\right.$,

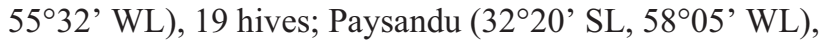
20 hives; Durazno ( $33^{\circ} 26^{\prime}$ SL, 56 $32^{\circ}$ ' WL), 20 hives; Rocha ( $33^{\circ} 29^{\prime}$ SL, $54^{\circ} 20^{\prime}$ WL), 20 hives; Mello (33⒌ SL, $54^{\circ} 12^{\prime}$ WL), 20 hives; Ombues de Lavalle ( $33^{\circ} 55^{\prime}$ SL, $57^{\circ} 48^{\prime}$ WL), 20 hives; and Montevideo (34 $54^{\circ}$ 'SL, 56 $04^{\circ}$ ' WL), 20 hives. The bees were transferred to glass tubes and kept at $-20{ }^{\circ} \mathrm{C}$ in the Genetics Laboratory at FMRP-USP. All samples were taken from colonies located in apiaries begun with captured swarms and unmanaged for queen replacement.

Total DNA of one adult worker thorax from each colony was extracted using published methods (Sheppard and McPheron, 1991). The DNA was digested with Eco RI endonuclease following manufacturer specifications. The restriction fragments generated by the enzyme were electrophoresed in $1.1 \%$ agar gels in TBE buffer for $5 \mathrm{~h}$ at $5 \mathrm{~V} / \mathrm{cm}$, stained with ethidium bromide $(0.01 \mathrm{mg} / \mathrm{mL})$, and visualized under UV light. The Eco RI restriction patterns of mtDNA make it possible to discriminate subspecies of African or European origin (Smith and Brown, 1988; Hall and Muralidharan, 1989; Sheppard et al., 1991a, Rinderer et al., 1991). Since direct Eco RI digestion of mtDNA produced no clear pattern, the cytochrome B locus was amplified by PCR and the fragment obtained was digested with $B g l$ II. Colonies classified as European (presence of the $B g l$ II site) had their mtDNA amplified for the COI-COII intergenic region and digested by $X b a I$, which revealed a restriction site in A. m. ligustica, but not in A. m. mellifera bees. The amplification and digestion products were analyzed by electrophoresis in $1.2 \%$ agar gels (at $5 \mathrm{~V} / \mathrm{cm}$ for $5 \mathrm{~h}$ ) stained with ethidium bromide and visualized under UV light. The primers used and the conditions for amplification and restriction were those described by Crozier et al. (1991) and Hall and Smith (1991).

Five bees per colony were electrophoretically analyzed for $M d h-1$ and $H k-1$ polymorphisms, as previously described by Del Lama et al. $(1988,1990)$. Mdh and $H k$ phenotypes were used to estimate allelic frequencies, verify genetic equilibrium of the populations for these loci and determine the racial admixture, according to the Krieger et al. (1965) method. F-statistics values, genetic distances among populations according to Nei (1978) and Cavalli-Sforza and Edwards (1967), and the respective dendrograms were estimated with the Biosys-1 program (Swofford and Selander, 1981). Linkage disequilibrium between $M d h-1$ and $H k$ loci was analyzed according to Weir (1990). Possible associations among nuclear and mitochondrial genotypes were verified by the Woolf test (1955) and by the method of Asmussen et al. (1987) for estimating the cytonuclear disequilibrium and its significance. This required grouping of the Mdh80 and Mdh65 alleles and respective genotypes, as they characterize European populations; the mtDNA patterns were classified as African (scutellata) or non-African haplotypes (mellifera, ligustica or "Portuguese").

\section{Results}

About $83 \%$ of the colonies exhibited the African mitochondrial type, which, however, was not uniformly distributed throughout the area studied. This finding made it possible to characterize two genetically distinct populations. The first was made up of colonies having only the African pattern (Santa Maria, Porto Alegre, Rivera, and Mello); the second group of populations was formed by colonies with African and European haplotypes, or having a high proportion of either an African (Paysandu, Durazno, and Rocha) or a European pattern (O. Lavalle and Montevideo) (see Table 1, Figure 1A).

Observed Mdh-1 and Hk-1 genotype frequencies in nine out of the ten populations were in accordance with the Hardy-Weinberg equilibrium model $\left(\chi^{2}\right.$ values shown in Table 2). Homogeneity tests showed significant differences for the $M d h-1\left(\chi^{2}=204.8 ; \mathrm{p}<0.001\right)$ and $H k\left(\chi^{2}=210.6\right.$; $\mathrm{p}<0.01)$ allele frequencies in these populations.

A negative correlation was found between the $M d h^{100}$ frequency and latitude $(\mathrm{r}=-0.76 ; \mathrm{p}=0.01)$ or longitude $(\mathrm{r}=-0.77 ; \mathrm{p}=0.009)$, while the $M d h^{80}$ frequency was significantly correlated with latitude $(r=0.77, p=0.009)$ and longitude $(r=0.74, p=0.01)$. No significant correlation

Table 1 - Distribution of mtDNA patterns (scutellata, ligustica, mellifera or Portuguese haplotypes) in bee populations from southern Brazil and Uruguay.

\begin{tabular}{lccccc}
\hline Localities & $\mathrm{n}$ & scutellata & mellifera & ligustica & Portuguese \\
\hline Santa Maria & 18 & $18(100 \%)$ & & & \\
Porto Alegre & 13 & $13(100 \%)$ & & & \\
Rivera & 17 & $17(100 \%)$ & & & \\
Paysandu & 19 & $15(79 \%)$ & $3(16 \%)$ & $1(5 \%)$ & \\
Durazno & 18 & $15(83 \%)$ & & & $3(17 \%)$ \\
Rocha & 17 & $16(94 \%)$ & & & $1(6 \%)$ \\
Mello & 20 & $20(100 \%)$ & & & \\
O.Lavalle & 13 & $4(31 \%)$ & $4(31 \%)$ & $5(38 \%)$ & \\
Montevideo & 20 & $10(50 \%)$ & $5(25 \%)$ & $5(25 \%)$ & \\
Total & 155 & $128(82.6 \%)$ & $12(7.7 \%)$ & $11(7.1 \%)$ & $4(2.6 \%)$ \\
\hline
\end{tabular}




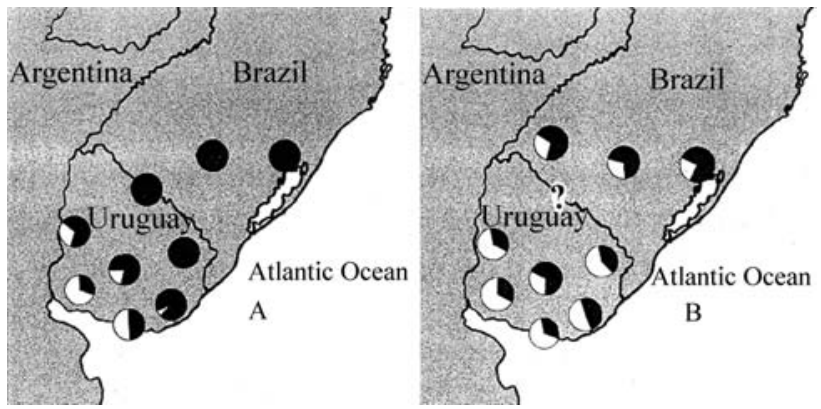

Figure 1 - A - Distribution of mtDNA haplotypes in honeybee populations sampled in Uruguay and southern Brazil. Black denotes proportion of haplotypes having African origin (A. m. scutellata), while white denotes proportion of haplotypes having European origin (A. m. ligustica, A. m. mellifera and Portuguese*). *See text. B - Admixture estimates for African and European subspecies contributions to population structure based on allozyme data. Black denotes relative contribution from African origin and white denotes contribution from combined European sources.

was observed between the $M d h^{65}$ frequency and latitude or longitude. A significant positive correlation was observed between the $H k^{100}$ frequency and latitude $(\mathrm{r}=-0.73$; $\mathrm{p}=0.016)$ or longitude $(\mathrm{r}=0.72 ; \mathrm{p}=0.02)$.

Racial admixture estimates (Table 3, Figure 1B) showed that the Santa Maria, Porto Alegre and Mello populations had similar racial compositions, with a high proportion of African genes (about 67\%), while the Paysandu, Durazno, Rocha, O. Lavalle and Montevideo populations had an Africanization level varying from $48 \%$ to $18 \%$, with the African component decreasing in populations farther to the southwest.

A highly significant $\mathrm{F}_{\mathrm{ST}}$ value was observed for the Mdh-1 $\left(\mathrm{F}_{\mathrm{ST}}=0.102 ; \chi^{2}=381.07, \mathrm{p}<0.001\right)$ and $H k$ $\left(\mathrm{F}_{\mathrm{ST}}=0.110 ; \chi^{2}=205.25, \mathrm{p}<0.001\right)$ loci. These results indicated genetically heterogeneous populations. A nonsignificant $\mathrm{F}_{\text {IS }}$ value corroborated the observation that the genotypic frequencies were in accordance with the genetic equilibrium model.
Table 3 - Racial admixture estimates in honeybee populations from southern Brazil and Uruguay, according to the Krieger et al. (1965) method, based on allele frequencies of $M d h-1$ and $H k$ loci (for parental frequencies, see Lobo et al., 1989).

\begin{tabular}{lccc}
\hline & \multicolumn{3}{c}{ Racial admixture estimates } \\
\cline { 2 - 4 } Localities & scutellata & mellifera & ligustica \\
\hline Santa Maria & $0.658 \pm 0.031$ & $0.284 \pm 0.031$ & $0.057 \pm 0.021$ \\
Alegrete & $0.684 \pm 0.065$ & $0.316 \pm 0.065$ & $0.010 \pm 0.000$ \\
Porto Alegre & $0.695 \pm 0.106$ & $0.304 \pm 0.106$ \\
Rivera & \multicolumn{3}{c}{ non convergent data } \\
Paysandu & $0.278 \pm 0.072$ & $0.662 \pm 0.080$ & $0.059 \pm 0.056$ \\
Durazno & $0.316 \pm 0.124$ & $0.684 \pm 0.124$ \\
Rocha & $0.480 \pm 0.044$ & $0.519 \pm 0.044$ \\
Mello & $0.642 \pm 0.088$ & $0.350 \pm 0.088$ \\
O. Lavalle & $0.182 \pm 0.138$ & $0.647 \pm 0.192$ & $0.169 \pm 0.198$ \\
Montevideo & $0.267 \pm 0.097$ & $0.733 \pm 0.097$ \\
\hline
\end{tabular}

Cavalli-Sforza and Edwards' genetic distances (Figure 2) clustered the populations into two groups: the first included the Santa Maria, Alegrete, Porto Alegre, Rivera and Mello populations; the Rocha, Paysandu, Durazno, O. Lavalle and Montevideo populations constituted the second group. A similar clustering was obtained using Nei's method (1978), except for the inclusion of the Rocha population in the cluster from southern Uruguay. This distribution fitted the mtDNA restriction patterns well and, as expected, the racial admixture estimates.

No evidence of linkage disequilibrium between the $M d h-1$ and $H k$ alleles was detected (Table 4), indicating no preferential associations among the $M d h$ and $H k$ genotypes in these bees. When all the populations were considered, a highly significant cytonuclear disequilibrium was found between the African:non-African haplotypes and the Mdh-1 phenotypes. However, such a disequilibrium was not found in populations in which both African and European mtDNA haplotypes were present. Furthermore, no as-

Table 2 - Allele frequencies and $\chi^{2}$ values for genetic equilibrium tests at the Mdh- 1 and $H k$ loci in Apis mellifera populations from southern Brazil and Uruguay.

\begin{tabular}{lccccccc}
\hline Localities & $M d h^{100}$ & $M d h^{80}$ & $M d h^{65}$ & $\chi^{2}$ & $H k^{100}$ & $H k^{87}$ & $\chi^{2}$ \\
\hline Santa Maria & $0.695 \pm 0.033$ & $0.268 \pm 0.032$ & $0.037 \pm 0.014$ & 0.290 & $0.563 \pm 0.035$ & $0.437 \pm 0.035$ & 0.004 \\
Alegrete & $0.699 \pm 0.031$ & $0.280 \pm 0.031$ & $0.018 \pm 0.009$ & 1.790 & $0.557 \pm 0.034$ & $0.443 \pm 0.034$ & 0.316 \\
Porto Alegre & $0.749 \pm 0.035$ & $0.240 \pm 0.035$ & $0.016 \pm 0.100$ & 1.382 & $0.600 \pm 0.040$ & $0.400 \pm 0.040$ & 0.000 \\
Rivera & $0.675 \pm 0.043$ & $0.325 \pm 0.043$ & & 2.433 & $0.592 \pm 0.044$ & $0.408 \pm 0.044$ & 0.283 \\
Paysandu & $0.350 \pm 0.033$ & $0.615 \pm 0.034$ & $0.035 \pm 0.013$ & 2.580 & $0.860 \pm 0.024$ & $0.140 \pm 0.024$ & 2.679 \\
Durazno & $0.410 \pm 0.035$ & $0.575 \pm 0.035$ & $0.015 \pm 0.010$ & 2.950 & $0.885 \pm 0.022$ & $0.115 \pm 0.022$ & $6.869 *$ \\
Rocha & $0.490 \pm 0.035$ & $0.500 \pm 0.035$ & $0.010 \pm 0.010$ & 5.816 & $0.682 \pm 0.033$ & $0.318 \pm 0.033$ & 0.005 \\
Mello & $0.680 \pm 0.033$ & $0.300 \pm 0.032$ & $0.020 \pm 0.010$ & 2.486 & $0.610 \pm 0.034$ & $0.390 \pm 0.034$ & 0.025 \\
O.Lavalle & $0.325 \pm 0.033$ & $0.590 \pm 0.035$ & $0.085 \pm 0.027$ & 1.495 & $0.950 \pm 0.015$ & $0.050 \pm 0.015$ & 0.030 \\
Montevideo & $0.335 \pm 0.033$ & $0.655 \pm 0.033$ & $0.010 \pm 0.010$ & 1.440 & $0.885 \pm 0.022$ & $0.115 \pm 0.022$ & 0.460 \\
\hline
\end{tabular}




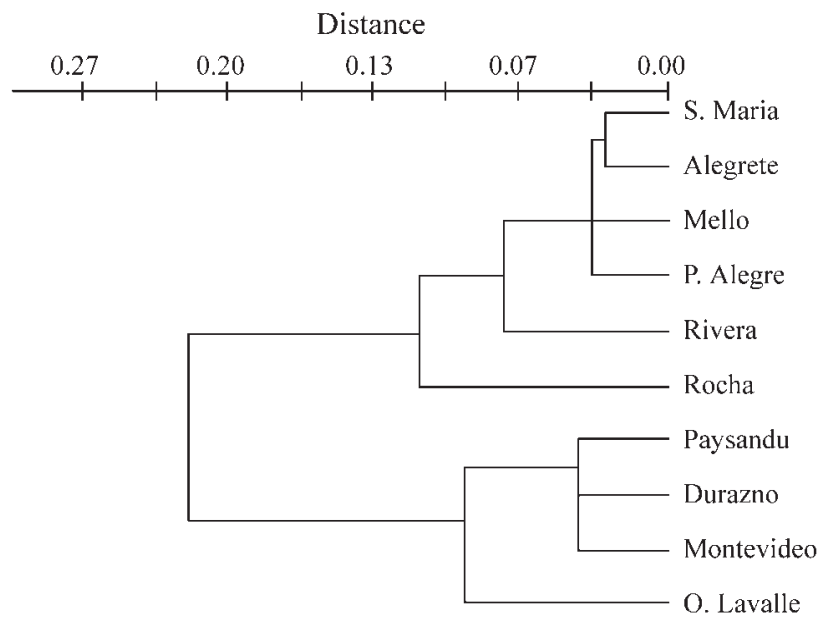

Figure 2 - Clustering analysis of genetic distances (Cavalli-Sforza and Edwards, 1967) among Africanized honeybee populations from southern Brazil and Uruguay using the UPGMA method of clustering.

Table 4 - Linkage disequilibrium coefficients (D \pm S.D.) between $M d h-1$ and Hk-1 loci in samples of Apis mellifera workers from southern Brazil and Uruguay.

\begin{tabular}{lcc}
\hline Localities & $\mathrm{D} \pm$ S.D. & $\chi^{2}$ \\
\hline Alegrete & $0.0031 \pm 0.0220$ & 0.0207 \\
Porto Alegre & $0.0065 \pm 0.0247$ & 0.0771 \\
Rivera & $-0.0369 \pm 0.0280$ & 0.5576 \\
Paysandu & $0.0069 \pm 0.0161$ & 0.1862 \\
Durazno & $-0.0105 \pm 0.0164$ & 0.6318 \\
Rocha & $-0.0022 \pm 0.0234$ & 0.0115 \\
Mello & $0.0332 \pm 0.0225$ & 0.3762 \\
O. Lavalle & $-0.1050 \pm 0.0107$ & 0.7921 \\
Montevideo & $-0.0014 \pm 0.0149$ & 0.0089 \\
\hline
\end{tabular}

sociation between nuclear and mitochondrial genotypes was found when cytonuclear disequilibrium or Woolf tests were applied to the Paysandu, Durazno, Rocha, O. Lavalle and Montevideo populations.

\section{Discussion}

Our results showed a high proportion of bee colonies with the African mtDNA haplotype, a finding similar to that described by Burgett et al. (1995). However, its geographic distribution was very heterogeneous. Colonies from southern Brazil and northern Uruguay had only the African type. Colonies with both African and European patterns were observed in localities farther south, sustaining the hypothesis that this area represents a zone of hybridization between Africanized and European bees (Kerr et al., 1982; Burgett et al., 1995).

Comparing our data with those previously described for Argentina (Sheppard et al., 1991a), we verified that southern Brazil and northern Uruguay, where bees with an exclusively African mtDNA haplotype were found, corresponded to the northern-most region described by those authors. The central region, or transition zone, in Argentina, where there was a lower proportion of swarms with African mtDNA, corresponded to the southern Uruguayan localities. Because it is located in more southerly latitudes than the areas we studied, the third zone described by Sheppard et al. (1991a), characterized by a low concentration of Africanized swarms, had no counterpart in Uruguay.

A new mtDNA pattern was detected in some colonies of the Rocha and Durazno samples. This haplotype was first reported in Argentine bees (Sheppard et al., 1991a). Although it was not found in a study by Sheppard et al. (1991a) carried out with samples from São Paulo state, it has subsequently been observed in that same region (Del Lama MA, unpublished observations). Evidence has recently been found that the probable Old World source of this pattern is Portugal, where it occurs in higher frequency than in Spain, where it is also found (W.S. Sheppard, unpublished observations; L. Garnery, unpublished observations).

Racial admixture estimates correlated well with the mtDNA results. Populations where colonies exhibited only the African haplotype (Santa Maria, Porto Alegre, Rivera and Mello) had a relatively high proportion of African genes (around 65\%). As the proportion of African genes in the other populations (Paysandu, Durazno, Rocha, O. Lavalle and Montevideo) decreased, so did the African mtDNA pattern proportion. However, these results demonstrated a certain degree of racial admixture even in populations where the African haplotype was fixed (southern Brazil and northern Uruguay). Although the first evidence obtained by the mtDNA analysis indicated an expansion of Africanized bees primarily as a continuous maternal African lineage (Smith et al., 1989; Hall and Muralidharan, 1989), nuclear genes clearly pointed to a certain degree of racial admixture, arguing against previous hypotheses that the continent was colonized by natural dispersion of the original African swarms.

Bee samples appeared to consist of almost exclusively of A. m. scutellata and A. m. mellifera nuclear genes. The Apis mellifera ligustica contribution to the hybrid was very low, with values close to zero, except for the Lavalle sample $(17 \%)$. However, the proximity of this region to Mercedes, where beekeeping is based on European bees usually imported from the USA, may explain this finding. A very small contribution of ligustica genes to the Africanized bee has also been demonstrated in samples from other Brazilian localities (Lobo et al., 1989; Del Lama et al., 1990). The low nuclear contribution of the ligustica subspecies to the Africanized hybrid contrasted with the similar frequencies of ligustica and mellifera mtDNA haplotypes, a discrepancy that has yet to be explained. 
Controversy over the relative contribution by Apis mellifera scutellata and European subspecies to the genetic makeup of Africanized honeybees has been engendered by apparent discordance of data from mitochondrial DNA (Smith et al., 1989; Hall and Muralidharan, 1989; Sheppard et al., 1991a,b) and allozymes or morphology (Lobo et al., 1989; Del Lama et al., 1990; Sheppard et al., 1991a,b). Allozymic and morphological character analyses suggest that about 20 to $30 \%$ of the genes of established populations of Africanized honeybees are of European ancestry (Lobo et al., 1989; Del Lama et al., 1990), whereas mtDNA haplotypes from such populations have been assigned almost exclusively to Apis mellifera scutellata (Smith et al., 1989; Hall and Muralidharan, 1989; Sheppard et al., 1991b). Hypotheses explaining the paucity of European mitochondrial DNA found in Africanized populations include subspecific differences in reproductive rates and other fitness parameters in the tropics, sizeable differences in colony densities, and asymmetrical fitness of hybrids with European or African matrilines.

However, assessment by Sheppard et al. (1999) using a composite haplotype approach, showed that mtDNA from honeybee colonies collected in Argentina was composed of a mixture of haplotypes most likely derived from both sub-Saharan and North African honeybee subspecies. Over $25 \%$ of the African mtDNA found in these Africanized colonies expressed a pattern found in North African honeybees (Apis mellifera intermissa from Morocco), but not in sub-Saharan Apis mellifera scutellata sources. Similar results were obtained in Africanized honeybee samples from nineteen Brazilian localities (K.M. Ferreira, unpublished results). These data could explain discrepancies among studies based on the allozyme, morphological, and mtDNA data reported above.

Genetic distance analysis according to the Nei (1978) or to the Cavalli-Sforza and Edwards (1967) similarly allowed the establishment of two population groups: the first included the samples from southern Brazil and northern Uruguay (Santa Maria, Alegrete, Porto Alegre, Rivera and Mello); the second clustered the populations from Paysandu, Durazno, Rocha, O. Lavalle and Montevideo. These results fitted the mtDNA and allozyme data well. Genetic distance between populations seemed to be associated with distances between them. Geographically closer bee populations showed lower interpopulational differentiation, suggesting a "stepping-stone" gene-flow model. A higher genetic flow among neighboring populations would be expected because bees do not travel distances large enough to alter the genetic structure of populations hundreds of kilometers away.

A clinal variation of the $M d h-1^{00}$ and $M d h-1^{80}$ allele frequencies with latitude was found. Latitudinal clines have been demonstrated at the Mdh-1 locus in natural populations in Italy (Badino et al., 1984) and in introduced populations in North and South America (Del Lama et al., 1990,
Lobo et al., 1989, Nielsen et al., 1994). These clines provide evidence that $M d h-1$ phenotypes experienced differential temperature-mediated selection; additional evidence for this assumption comes from the differences in the thermostability of Mdh-1 allozymes (Cornuet et al., 1995). However, these clines have also been regarded as evidence for hybridization events rather than selection (Badino et al., 1984; Del Lama et al., 1990, Lobo et al., 1989, Smith and Glenn, 1995). Clinal variation of the Mdh-1 alleles observed in our samples could be better explained by hybridization than by selection because parallel clines were observed for $H k$ alleles and mellifera mtDNA haplotypes.

Absence of gametic disequilibrium among the $M d h$ and $H k$ alleles indicated no gametic preferential association of the $M d h-1$ and $H k-1$ alleles. A highly significant cytonuclear disequilibrium between the African mitochondrial haplotype and the $M d h^{100}$ allele was observed when all samples were considered. However, this disequilibrium merely reflected the inclusion of populations whose colonies have only the African mtDNA haplotype. When the populations which segregate African and European haplotypes were analyzed, the cytonuclear disequilibrium was no longer observed. These findings indicated that there were no preferential associations among nuclear and mitochondrial markers, a result also confirmed by the Woolf test.

Our results confirmed the existence of a transition area of genetically distinct honeybee populations in Southern Brazil and Uruguay and that the southern limit of occupation in South America by Africanized colonies was located between the $30^{\circ}-35^{\circ}$ parallels. Because of random mating (Mdh-1 and $H k-1$ loci are under genetic equilibrium, and non-significant $\mathrm{F}_{\mathrm{IS}}$ values), absence of gametic disequilibrium between these loci, and absence of citonuclear disequilibrium among nuclear and mitochondrial markers, we considered that the Africanization process of the honeybee populations of Uruguay has been completed.

\section{Acknowledgments}

Permission for sample collection was granted to us by Mr. Juan Cordara in the name of the Uruguayan government. We are also thankful to Mr. Raul Paixão Coelho; to Mathew, a peace corps volunteer, and to the Uruguayan beekeepers for help in bee sampling. Many thanks are also due to the southern Brazilian beekeepers for collecting and shipping their samples. This study was sponsored by FINEP and CNPq.

\section{References}

Asmussen HB, Arnold J and Avise JC (1987) Definition and properties of disequilibrium statistics for associations between nuclear and cytoplasmic genotypes. Genetics 115:755-768.

Badino G, Celebrano G and Manino A (1983) Population structure and Mdh-1 locus variation in Apis mellifera ligustica. $\mathrm{J}$ Hered 74:443-446. 
Badino G, Celebrano G and Manino A (1984) Population genetics of Italian honeybee (Apis mellifera ligustica Spin.) and its relationships with neighbouring subspecies. Boll Mus Reg Sci Nat Torino 2:571-584.

Burgett M, Shorney S, Cordara J, Gardiol G and Sheppard WS (1995) The present status of Africanized honey bees in Uruguay. Am Bee J 135:328-330

Cavalli-Sforza LL and Edwards AWF (1967) Phylogenetic analysis: Models and estimation procedures. Am J Hum Genet 19:233-257.

Clarke KE, Oldroyd BP, Quezada-Euán JJG and Rinderer TE (2001) Origin of honeybees (Apis mellifera L.) from the Yucatan peninsula inferred from mitochondrial DNA analysis. Mol Ecol 10:1347-1355.

Cornuet JM, Oldroyd BP and Crozier RH (1995) Unequal thermostability of allelic forms of malate dehydrogenase in honey bees. J Apic Res 34:45-47.

Crozier YC, Koulianos S and Crozier RH (1991) An improved test for Africanized honeybee mitochondrial DNA. Experientia 47:968-969.

Del Lama MA, Figueiredo RA, Soares AEE and Del Lama SN (1988) Hexokinase polymorphism in Apis mellifera and its use for Africanized honeybee identification. Braz J Genet 11:287-297.

Del Lama MA, Lobo JA, Soares AEE and Del Lama SN (1990) Genetic differentiation estimated by isozymic analysis of Africanized honeybee population from Brazil and from Central America. Apidologie 21:271-280.

Estoup A, Solignac M, Harry M and Cornuet JM (1993) Characterization of (GT)n and (CT)n microsatellites in two insect species: Apis mellifera and Bombus terrestris. Nucleic Acids Res 21:1427-1431

Estoup A, Solignac M and Cornuet JM (1994) Precise assessment of the number of matings and of relatedness in honey bee colonies. Proc R Soc Lond B 258:1-7.

Franck P, Garnery L, Solignac M and Cornuet JM (1998) The origin of west European subspecies of honeybees (Apis mellifera): new insights from microsatellite and mitochondrial data. Evolution 52:1119-1134.

Hall HG (1986) DNA differences found between Africanized and European honeybees. Proc Natl Acad Sci USA 83:48744877.

Hall HG (1990) Parental analysis of introgressive hybridization between African and European honeybees using nuclear DNA RFLPs. Genetics 125:611-621.

Hall HG and Muralidharan K (1989) Evidence from mitochondrial DNA that African honey bees spread as continuous maternal lineages. Nature 339:211-213.

Hall HG and Smith DR (1991) Distinguishing African and European honeybee matrilines using amplified mitochondrial DNA. Proc Natl Acad Sci USA 88:4548-4552.

Kerr WE (1967) The history of the introduction of African Bees to Brazil. South Afric Bee J 39:3-5.

Kerr WE, De Leon S and Dardo M (1982) The southern limits of the distribution of the Africanized honeybee in South America. Am Bee J 122:196-198.

Krieger H, Norton NE, Mi MP, Azevedo E, Freire-Maia A and Yasuda N (1965) Racial admixture in north-eastern Brazil Ann Hum Genet 29:113-125.
Lobo JA (1995) Morphometric, isozymic and mitochondrial variability of Africanized honeybees in Costa Rica. Heredity 75:133-141.

Lobo JA, Del Lama MA and Mestriner MA (1989) Population differentiation and racial admixture in the Africanized honeybee (Apis mellifera L.). Evolution 43:794-802.

Nei M (1978) Estimation of average heterozygosity and genetic distance from a small number of individuals. Genetics 89:583-590.

Nielsen D, Page RE and Crosland MWJ (1994) Clinal variation and selection of allozymes in honey bee populations. Experientia 50:867-871.

Oldroyd BP, Sheppard WS and Stelzer JA (1992) Genetic characterization of the bees of Kangaroo Island, South Australia. J Apic Res 31:141-148.

Rinderer TE, Stelzer JA, Oldroyd BP, Buco SM and Rubink WL (1991) Hybridization between European and Africanized honey bees in the Neotropical Yucatan Peninsula. Science 253:309-311.

Rowell M, Bradley LA and Cole CL (1993) The range expansion of the Africanized honeybee in Texas. Am Bee J 133:84-85.

Sanford M (1995) Screening for African bees. Florida Extension Beekeeping Newsletter-Apis 12:17

Sheppard WS and McPheron BA (1986) Genetic variation in honey bees from an area of racial hybridization in western Czechoslovakia. Apidologie 17:21-32.

Sheppard WS and McPheron BA (1991) Ribosomal DNA diversity in Apidae. In: Smith DR (ed) Diversity in the genus Apis. Westview, Boulder, pp 89-102.

Sheppard WS, Rinderer TE, Mazzoli JA, Stelzer JA and Shimanuki H (1991a) Gene flow between African- and European-derived honey bee populations in Argentina. Nature 349:782-784.

Sheppard WS, Soares AEE, De Jong D and Shimanuki H (1991b) Hybrid status of honey bee population near the historic origin of Africanization in Brazil. Apidologie 22:643-652.

Sheppard WS, Rinderer TE, Garnery L and Shimanuki H (1999) Analysis of Africanized honey bee mitochondrial DNA reveals further diversity of origin. Genet Mol Biol 22:73-75.

Smith DR and Brown WM (1988) Polymorphisms in mitochondrial DNA of European and Africanized honeybees (Apis mellifera). Experientia 44:257-260.

Smith DR and Glenn TC (1995) Allozyme polymorphisms in Spanish honeybees (Apis mellifera iberica). J Hered 86:1216.

Smith DR, Taylor OR and Brown WM (1989) Neotropical Africanized honey bees have African mitochondrial DNA. Nature 339:213-215

Spivak M, Ranker T, Taylor OR, Taylor W and Davis L (1988) Discrimination of Africanized honeybees using behavior, cell size, morphometrics, and a newly discovered isozyme polymorphism. In: Needham GR, Page REJr, DelfinadoBaker $\mathrm{M}$ and Bowman CE (eds) Africanized honey bees and bee mites. Ellis Horwood, Chichester, pp 313-324.

Swofford DL and Selander RB (1981) Biosys-1: a Fortran program for the comprehensive analysis of electrophoretic data in population genetics and systematics. J Hered 72:281-283.

Weir BS (1990) Genetic data analysis: Methods for discrete population genetic data. Sinauer, Sunderland, $377 \mathrm{pp}$.

Woolf B (1955) On estimating the relation between blood and disease. Ann Hum Genet 19:251-253. 